\title{
ВMJ Global Health COVID-19 stressors on migrant workers in Kuwait: cumulative risk considerations
}

\author{
Barrak Alahmad (D ) ${ }^{1,2}$ Hussam Kurdi, ${ }^{1}$ Kyle Colonna, ${ }^{1}$ Janvier Gasana, ${ }^{2}$ \\ Jacqueline Agnew, ${ }^{3}$ Mary A Fox ${ }^{4}$
}

\begin{abstract}
To cite: Alahmad B, Kurdi $\mathrm{H}$, Colonna $\mathrm{K}$, et al. COVID-19 stressors on migrant workers in Kuwait: cumulative risk considerations. BMJ Global Health

2020;5:e002995. doi:10.1136/ bmjgh-2020-002995
\end{abstract}

Handling editor Seye Abimbola

Received 25 May 2020

Revised 16 June 2020

Accepted 19 June 2020

Check for updates

(C) Author(s) (or their employer(s)) 2020. Re-use permitted under CC BY-NC. No commercial re-use. See rights and permissions. Published by BMJ.

${ }^{1}$ Environmental Health Department, Harvard T.H. Chan School of Public Health, Harvard University, Boston, Massachusetts, United States ${ }^{2}$ Department of Environmental and Occupational Health, Faculty of Public Health, Kuwait University, Hawalli, Kuwait ${ }^{3}$ Department of Environmental Health and Engineering and Johns Hopkins Education and Research Center for Occupational Safety and Health, Johns Hopkins Bloomberg School of Public Health, Baltimore, Maryland, United States

${ }^{4}$ Department of Health Policy and Management and Risk Sciences and Public Policy Institute, Johns Hopkins Bloomberg School of Public Health, Baltimore, Maryland United States

Correspondence to Dr Barrak Alahmad b.alahmad@g.harvard.edu

\section{ABSTRACT}

As a marginalised subpopulation, migrant workers often fall short from protection by public policies, they take precarious jobs with unsafe working and living conditions and they grapple with cultural and linguistic barriers. In light of the current COVID-19 pandemic, migrant workers are now exposed to additional stressors of the virus and related responses. We applied a comprehensive qualitative cumulative risk assessment framework for migrant workers living in Kuwait. This pandemic could be one of the few examples where the stressors overlap all domains of migrant workers' lives. No single intervention can solve all the problems; there must be a set of interventions to address all domains. Local authorities and employers must act quickly to stop the spread, ensure easy access to testing and treatment, provide adequate housing and clear communication, encourage wide social support, safeguard financial protection and mental well-being and continuously re-evaluate the situation as more data are collected.

\section{BACKGROUND}

Nearly $3.3 \%$ of the world's population lives outside their home country, and half of them are estimated to be migrant workers. ${ }^{1}$ In many countries, migrant workers are recognised as one of the most vulnerable subpopulations, as they: (1) often are excluded from protections provided by public policies; (2) frequently take precarious jobs with less pay and longer hours; (3) often work in unsafe working conditions with little occupational safety and health (OSH) training; and (4) grapple with major cultural and language barriers. ${ }^{12}$

On 11 March 2020, the WHO declared that the infectious COVID-19 outbreak caused by the severe acute respiratory syndrome coronavirus 2, is a pandemic. Since its initial cluster of pneumonia cases in Wuhan, China, the virus has infected millions and caused hundreds of thousands of deaths globally.

Migrant workers are particularly susceptible to this infection-an additional stressor combined with those identified above.
Summary box

A large migrant worker population in Kuwait faced precarious living and working conditions prior to the emergence of COVID-19.

- This work applies a cumulative risk assessment framework to qualitatively assess the overlapping individual, community, environmental and occupational exposures of migrant workers to inform public health interventions.

- The health of workers and the broader populace is inextricably linked through overlapping factors.

- Risk management will require a set of interventions including: disease containment, mitigation and prevention; healthcare access; temporary housing; information access; worker protection; community support; and continuous monitoring and adjustment as conditions change.

Understanding the detrimental effects of COVID-19 alone on workers' health may not be sufficient. Recent OSH risk assessment frameworks and methods have advanced towards cumulative risk assessment (CRA). ${ }^{3}$ These cumulative frameworks recognise that an occupational exposure to a contagion like COVID-19 does not occur in isolation from other stressors. In light of the current pandemic, we anticipate that employers and authorities must now address the variable job health and safety needs of migrant workers.

In Kuwait, there is a considerable heterogeneity with regards to vulnerable employment and extreme working poverty. Non-Kuwaiti migrant workers make up more than $60 \%$ of the total population and are mostly employed in low-skilled sectors and domestic work. ${ }^{4}$ About $70 \%$ of non-Kuwaitis are males, and only $20 \%$ of non-Kuwaitis have educational attainment of high-school or higher. ${ }^{4}$ The majority of the migrant non-Kuwaiti subpopulation come to the country unaccompanied by their families. Striking differences in health outcomes attributable to 


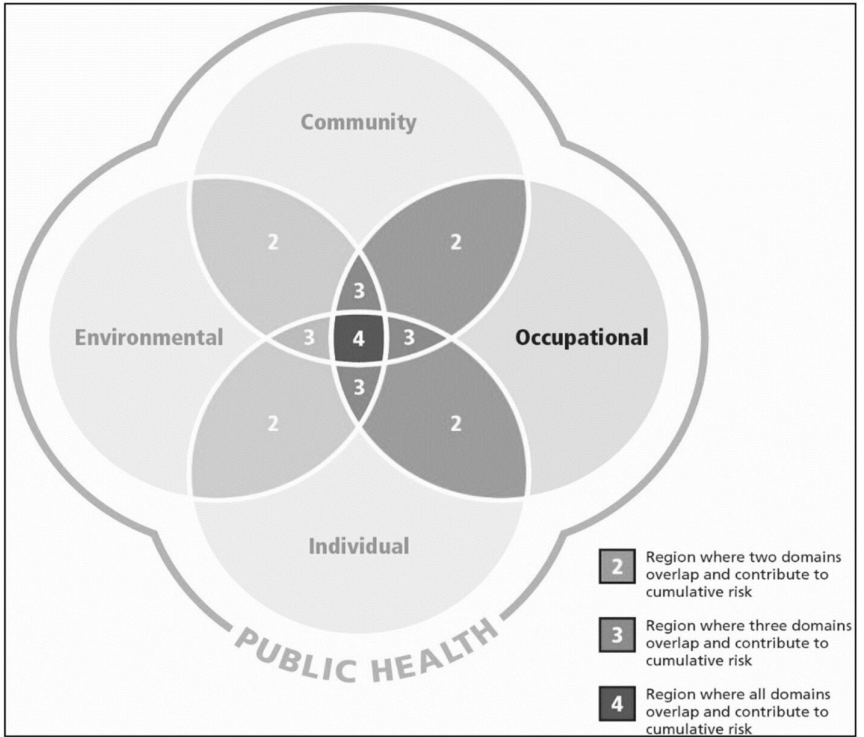

Figure 1 A cumulative risk assessment framework for occupational health and safety with four overlapping domains described by Fox et al. ${ }^{3}$ The occupational domain (highlighted) cannot be viewed in isolation from other domains.

environmental exposures such as heat and air pollution between the Kuwaiti and the non-Kuwaiti subpopulations have been recently documented. ${ }^{56}$ This work investigates the multiple stressors associated with the COVID-19 pandemic on migrant workers by applying a holistic CRA framework, using Kuwait as an example. Furthermore, we use the framework to suggest potential interventions for individuals, employers and authorities to improve the health of migrant workers in the country.

\section{APPROACH}

The conventional risk assessment process is typically applied to address one hazard at a time. In reality, workers are often exposed to multiple hazards at any given time. The US Environmental Protection Agency defines cumulative risk as 'the combined risks from aggregate exposures to multiple agents or stressors'. ${ }^{7}$ In this paper, we will apply a workplace CRA framework that was presented by Fox $e t a l{ }^{3}$ In brief, the framework acknowledges that multiple stressors in different domains can interact with each other resulting in cumulative risk that can then be used to inform new risk management approaches, exposure reduction and prevention strategies. The model assumes that stressors arise from four dynamic interactive domains: the workplace (occupational); ambient environment; individual (behaviour and genetic); and community (family and other social interactions) (figure 1).

This CRA framework will provide a qualitative evaluation of multiple stressors affecting migrant workers in Kuwait (table 1). We apply the framework in a stepwise process starting with identifying the importance and scope of the problem, that is, why it should matter and who should care (step 1). Steps 2-5 assess the target population, the stressors/hazards, the overall pattern of health among the target population and consider the interactions between stressors and the domains. Finally, we propose potential interventions in light of the findings from the previous steps (step 6).

\section{IMPORTANCE OF PROBLEM}

The first confirmed cases in Kuwait occurred on 24 February 2020, among four Kuwaiti passengers who arrived on an evacuation flight from Iran. Since then, more than $80 \%$ of the total cases have been non-Kuwaiti nationals (https://corona.e.gov.kw/). The situation is not much different in other Gulf states. Uncontrolled outbreaks within clusters of migrant workers can result in catastrophic outcomes including the loss of many lives, an overwhelmed healthcare system and other deleterious economic losses. However, even if the spread of the infection is controlled, enforced lockdowns and business closures can have dire consequences for migrant workers.

\section{Populations of interest}

Most migrant workers in Kuwait are men from South and Southeast Asia. Examples of essential non-healthcare migrant work in Kuwait include staffing in the retail and food, transportation, security and construction industries. These workers are continuously interacting with the rest of their community and may potentially contract the disease from infectious individuals. Migrant workers who are in non-essential businesses that remain closed could

Table 1 Application of a CRA framework to COVID-19 stressors among migrant workers

\begin{tabular}{lll}
\hline & Steps & Simplifying questions \\
\hline 1 & Importance of problem & Why does the COVID-19 outbreak among migrant workers matter and who should care? \\
\hline 3 & $\begin{array}{l}\text { Populations of interest } \\
\text { Potential stressors/hazards }\end{array}$ & $\begin{array}{l}\text { Which migrant workers are disproportionately affected by COVID-19? } \\
\text { and in what domains? }\end{array}$ \\
4 & Exposure patterns & How do these stressors from step 3 contribute to the overall health of migrant workers? \\
5 & CRA considerations & How do these stressors interact and overlap across all four domains for migrant workers? \\
6 & Potential interventions & $\begin{array}{l}\text { What risk management approaches, exposure reduction strategies and OSH prevention } \\
\text { measures can be applied to migrant workers affected by COVID-19? }\end{array}$
\end{tabular}

CRA, cumulative risk assessment; $\mathrm{OSH}$, occupational safety and health. 
be living in labour camps outside the city or in other cramped dormitories.

\section{Potential stressors/hazards \\ The workplace}

Several dangerous trades occupied by migrant workers present health threats from chemical and physical exposures, often existing as mixtures or in combinations. Issues associated with these hazards can be significantly amplified among migrant workers due to language and cultural barriers. As a consequence, the effectiveness of any occupational prevention measure (eg, work practices and wearing personal protective equipment) can be compromised. Language barriers also make it difficult for migrant workers to report symptoms or raise concerns with their managers. Training on measures such as social distancing and/or hygiene instructions may not be supported for the typical wide range of languages among worker populations.

\section{The environment}

A large proportion of migrant workers in Kuwait live in cramped dormitories with poor housing conditions: small rooms with tens of men living together; unmaintained and shared toilets; poor or no ventilation; and high risk of bed bugs and other pests. Such environments with consistent close proximity among occupants have the potential to increase COVID-19 outbreaks among migrant workers. In addition, there are environmental exposures like heatwaves and air pollution that can independently increase vulnerability and promote comorbidities; migrant workers in Kuwait have been shown to be especially vulnerable to air pollution. ${ }^{6}$

\section{The community}

Nearly $70 \%$ of the non-Kuwaiti subpopulation are males. ${ }^{4}$ The majority are not accompanied by their families. Their distant families rely on them for financial support (eg, transferring money and shipping goods) to meet basic needs such as paying school fees and getting food. For many households in the receiving countries, money from migrant workers is likely the sole source of cash. However, migrants are often employed in less secure or precarious jobs with no permanent employment contract. This imposes significant job uncertainty. The current pandemic undoubtedly has compounded severe financial hardship and interpersonal difficulties within families who may not be able to survive job loss or delayed payments.

Returning home is rarely an option. During the COVID-19 induced lockdowns, migrant workers will likely face mounting debts, unemployment and difficulties in daily living. The lockdowns in workers' home countries have had enormous negative impacts on daily wages of labourers who were unable to earn their daily living and were not able to move. ${ }^{8}$ These stressors are difficult to address since the political climate in the host country may also bring about xenophobia, suspicion and unequal rights.

The current immigration system in Kuwait and other Gulf states (the Kafala system) requires all migrant workers to have an in-country sponsor for their visa and legal status. This system restricts changing employers and has been associated with trafficking and forced labour. ${ }^{29}$ It is unlikely that workers would have an option to transfer to jobs with less risk of exposure to COVID-19.

\section{The individual}

Although a large proportion of migrant workers in Kuwait are young and healthy, those living with comorbidities, some of which might be due to work-related illnesses or injuries, may be more vulnerable to the effects of COVID19. We do not have data on the prevalence of unhealthy behaviours that can increase the risk of severe COVID-19 illness, such as smoking or diet. Furthermore, there might be difficulty accessing healthcare due to documentation status, limited knowledge of health coverage, costs and poverty.

\section{Exposure patterns}

Without serviceable command of the local language, migrant workers were found to be likely to take more dangerous jobs and incur occupational injuries. ${ }^{10}$ Additionally, the constantly changing COVID-19 lockdown and curfew messages may not reach migrant workers, putting them in legal jeopardy. Violating curfew is a serious offence in Kuwait that could lead to deportation for non-nationals. In addition, migrant workers experience difficulty communicating with medical professionals, have little knowledge of the health insurance systems and report lack of access to interpreters. ${ }^{2}$ All these factors contribute to low turnout at testing stations and treatment centres for COVID-19. In addition, such barriers to healthcare utilisation may result in delayed presentation for a number of days before seeking help, likely affecting the severity of outcomes from the infection.

There have been numerous reports of person-to-person transmission of COVID-19 within the same household. ${ }^{11}$ High air exchange rates, proper use and disinfection of toilets, and open spaces were associated with lower aerosol transmission of COVID-19. ${ }^{12}$ Self-isolation is nearly impossible. People living in areas with high outdoor air pollution levels were shown to be at higher risk of dying from COVID-19. ${ }^{13}$ Although social lockdowns have substantial positive impact on the overall environment and air pollutants, especially $\mathrm{NO}_{2}$ and particulate matter, ${ }^{14}$ it is unclear how this reduction in short-term exposure can translate into public health gains for migrant workers.

Individuals with low educational attainment and low income are more likely to be exposed to factors contributing to poor health compared with those with more socioeconomic resources. ${ }^{15}$ Additionally, stress from the uncertainty of precarious jobs and fear of job loss or deportation can have negative mental health outcomes. ${ }^{216}$ 
Other mental disorders can also be exacerbated by financial hardship for migrant workers who are no longer able to send money to their families because of the lockdown orders. ${ }^{17}$ Beyond mental health, stress is also associated with premature death and coronary heart disease ${ }^{18}$ With regard to behavioural factors, there is some evidence that smoking is associated with poor progression and health outcomes from COVID-19 exposures. ${ }^{19} 20$

\section{CRA considerations}

Even when we only focus on the health impacts of COVID-19 on workers in the occupational domain, we saw a strong influence from other related stressors originating from sources across all domains. Considering figure 1, COVID-19 adds to the existing serious health risks experienced by migrant workers in Kuwait. Put another way, this pandemic could be one of the few examples where the risk overlaps all aspects of migrant workers' lives (as seen in shaded area 4-figure 1). No single intervention can solve all the problems outlined; rather, a set of interventions that address all domains is in order.

\section{Potential interventions}

We propose a holistic approach to this multidimensional problem for the migrant workers in Kuwait, consistent with the global call to action to protect migrant health from COVID-19. ${ }^{21}$

\section{Stop the spread (community/individual)}

The prevalence and incidence of infection among migrant workers are not known. Kuwait has taken many public health control measures to stop and slow down the spread of COVID-19, including closures of schools and universities, closures of all non-essential businesses, a full border lockdown and a partial curfew. When the disease started spreading in areas populated by migrant workers, the government enforced zonal isolation. Outreach to migrant worker communities to educate about the symptoms of illness and its prevention and active public health surveillance efforts are needed to identify cases at an early stage and prevent the progression to severe illness as well as reduce the number of people who could potentially get infected. Ideally, health authorities would employ testing to further understand the distribution and the spread of the disease although capacity to test remains limited in many places. Absent testing, monitoring hospitalisations and deaths linked with contact investigations help identify and move cases into treatment.

\section{Healthcare access (community/individual)}

Migrant workers should have free access to testing and treatment for COVID-19. Easy-access facilities should include drive-through and walk-in testing. These are alternative solutions for temporary testing operations that can reduce patient-provider exposure and accelerate test administration. For example, large segments of the migrant workers subpopulation may not have access to cars; therefore, a walk-in testing booth is an appropriate option. Similarly, mobile clinics and field hospitals in underserved areas can be very important to protect vulnerable marginalised groups from COVID-19. Free health services including health education, screening and advice can be provided by mobile clinics. Workers who do not live near hospitals and do not have access to adequate transportation can benefit the most. In addition, unlawful migrant workers may be reluctant to report symptoms or access testing facilities because they fear detention and deportation. This reluctance can carry a significant risk to the health of these workers and that of the community. In the short term, let public health take precedence over enforcement; immigration authorities should send clear messages to encourage unlawful migrant workers to get COVID-19 tests and report symptoms.

\section{Temporary housing (workplace/environment/community)}

Many workers may not be able to effectively self-isolate should they test positive for COVID-19. In cases where housing conditions cannot be adjusted to new social distancing protocols, the government has to work with employers to consider some form of separate temporary housing for migrant workers who test positive. These include hotels and other temporary housing on work sites. Moving forward, the authorities need to create a long-term plan to improve the living facilities for all workers.

\section{Information access (workplace/community)}

Migrant workers may be at risk of being penalised for unknowingly breaking curfew laws. The government must work with the relevant embassies to provide workers with information on COVID-19 in a language they understand. Similarly, employers must have training programmes that incorporate methods that transcend linguistic and cultural barriers such as pictograms, illustrations and hands-on exercises. ${ }^{22}$

\section{Worker protection (workplace/community)}

Many workers are now facing layoffs, furloughs, nonpayment and late payment of wages putting them in significant financial hardship. The government and employers should reach some mutual agreement to continue paying workers living in isolated zonal areas or under health quarantine. Any gaps in financial support to workers should be adequately covered.

\section{Community support (environment/community/individual)}

Many individuals and organisations are putting in enormous time and effort to provide relief for migrant workers in Kuwait. Community volunteers, charity organisations, donors and non-profit organisations should come together to raise funds to cover basic necessities for migrant workers such as meals, masks and sanitary supplies. Community support can go beyond daily essentials towards mental well-being of workers through implementing mental health programmes, provision of internet connectivity and prepaid phones for worker to contact their families. 
Continuous evaluation (all domains)

Implemented policies must be continuously reassessed in light of the fast-changing situation and new data. It is key that policy evaluation is carried out at a high temporal (daily monitoring) and spatial (household level) resolution. That is, there should be careful monitoring of the number of new confirmed cases, deaths, hospitalisations and admissions to intensive care among migrant workers. Furthermore, geospatial mapping of cases through geographic information systems are critical for identifying emerging clusters.

\section{CONCLUSION}

Migrant workers are a marginalised subpopulation in Kuwait. They often fall short of protection by public policies, face language and cultural barriers and take precarious jobs with more hazards, less pay and longer hours. The COVID-19 pandemic has placed multiple extraordinary stressors on migrant workers in Kuwait both on and off the job. We applied a cumulative risk assessment framework that enabled us to assess stressors on migrant workers in the workplace, environment, community and individual domains. We used the framework to inform new risk management approaches and exposure reduction strategies that address these multiple stressors. Although our assessment lacked quantitative data, we highlighted the type of data that would be needed to ensure continuous re-evaluation. This may be resource intensive (money, people and time), but a coordinated effort aimed at key social supports will have substantial health benefits for the entire community. This cumulative risk assessment framework for migrant workers in Kuwait can be applied in other countries and different settings.

\section{Twitter Barrak Alahmad @barrak1}

Acknowledgements As part of the Emergency Resilience Program in Kuwait, led by Kuwait Foundation for the Advancement of Sciences (KFAS), this project was funded by KFAS under the project code: CORONA PROP 134, titled: 'Strengthening Capacity for Protection of Occupational Health and Safety of Health Care Workers and Non-healthcare Workers During COVID-19 Pandemic and Beyond'. Authors have no conflicts to declare. Figure 1 was reprinted from Environment International publication, 115: 230-238, doi: 10.1016/j.envint.2018.03.026, Mary A Fox, Kristen Spicer, L Casey Chosewood, Pam Susi, Douglas 0 Johns and G Scott Dotson, Implications of applying cumulative risk assessment to the workplace, copyright (June 2018), with permission from Elsevier.

Contributors Concept and design: BA and MAF. Acquisition, analysis or interpretation of data: all authors. Drafting of the manuscript: BA. Critical revision of the manuscript for important intellectual content: all authors. Supervision: JG and MAF.

Funding This project was funded by Kuwait Foundation for the Advancement of Sciences (KFAS) under the project code: CORONA PROP 134.

Competing interests None declared.

Patient consent for publication Not required.

Provenance and peer review Not commissioned; externally peer reviewed.
Data availability statement № additional data are available.

Open access This is an open access article distributed in accordance with the Creative Commons Attribution Non Commercial (CC BY-NC 4.0) license, which permits others to distribute, remix, adapt, build upon this work non-commercially, and license their derivative works on different terms, provided the original work is properly cited, appropriate credit is given, any changes made indicated, and the use is non-commercial. See: http://creativecommons.org/licenses/by-nc/4.0/.

ORCID iD

Barrak Alahmad http://orcid.org/0000-0002-9523-9537

\section{REFERENCES}

1 International Labour Organization (ILO). ILO global estimates on migrant workers: results and methodology. Geneva: International Labour Office, 2015. https://www.ilo.org/global/publications/books/ WCMS_652001/lang--en/index.htm

2 Moyce SC, Schenker M. Migrant workers and their occupational health and safety. Annu Rev Public Health 2018;39:351-65.

3 Fox MA, Spicer K, Chosewood LC, et al. Implications of applying cumulative risk assessment to the workplace. Environ Int 2018;115:230-8.

4 PACI. The public authority for civil information. Government of Kuwait, 2019

5 Alahmad B, Shakarchi AF, Khraishah H, et al. Extreme temperatures and mortality in Kuwait: who is vulnerable? Sci Total Environ 2020;732:139289.

6 Achilleos S, Al-Ozairi E, Alahmad B, et al. Acute effects of air pollution on mortality: a 17-year analysis in Kuwait. Environ Int 2019;126:476-83.

7 U.S. Environmental Protection Agency (EPA). Framework for cumulative risk assessment. EPA/600/P-02/001F. Washington, D C: U.S. environmental protection agency, 2003. https://www.epa.gov/ risk/framework-cumulative-risk-assessment

8 Paital B, Das K, Parida SK. Inter nation social lockdown versus medical care against COVID-19, a mild environmental insight with special reference to India. Sci Total Environ 2020;728:138914.

9 Jureidini R. Trafficking and contract migrant workers in the middle East. Int Migr 2010;48:142-63.

10 Orrenius PM, Zavodny M. Do immigrants work in riskier jobs? Demography 2009;46:535-51.

11 Chan JF-W, Yuan S, Kok K-H, et al. A familial cluster of pneumonia associated with the 2019 novel coronavirus indicating personto-person transmission: a study of a family cluster. Lancet 2020;395:514-23.

12 Liu Y, Ning Z, Chen Y, et al. Aerodynamic analysis of SARS-CoV-2 in two Wuhan hospitals. Nature 2020;582:557-60.

13 Wu X, Nethery RC, Sabath BM, et al. Exposure to air pollution and COVID-19 mortality in the United States. medRxiv 2020.

14 Paital B. Nurture to nature via COVID-19, a self-regenerating environmental strategy of environment in global context. Sci Total Environ 2020;729:139088.

15 Adler NE, Boyce T, Chesney MA, et al. Socioeconomic status and health. The challenge of the gradient. Am Psychol 1994;49:15-24.

16 Tsai JH-C, Thompson EA. Effects of social determinants on Chinese immigrant food service workers' work performance and injuries: mental health as a mediator. J Occup Environ Med 2015;57:806-13.

17 Liem A, Wang C, Wariyanti Y, et al. The neglected health of international migrant workers in the COVID-19 epidemic. Lancet Psychiatry 2020;7:e20.

18 Steptoe A, Kivimäki M. Stress and cardiovascular disease. Nat Rev Cardiol 2012;9:360-70.

19 Vardavas CI, Nikitara K. COVID-19 and smoking: a systematic review of the evidence. Tob Induc Dis 2020;18:20.

20 Cai H. Sex difference and smoking predisposition in patients with COVID-19. Lancet Respir Med 2020;8:e20.

21 Orcutt M, Patel P, Burns R, et al. Global call to action for inclusion of migrants and refugees in the COVID-19 response. Lancet 2020;395:1482-3.

22 De Jesus-Rivas M, Conlon HA, Burns C. The impact of language and culture diversity in occupational safety. Workplace Health Saf 2016;64:24-7. 